\title{
Editorial cartoon collections: a review of indexing challenges
}

\author{
Oliver Stead \\ Alexander Turnbull Library, National Library of New Zealand, \\ Wellington, New Zealand, and \\ Chern Li Liew \\ School of Information Management, Victoria University of Wellington, \\ Wellington, New Zealand
}

\begin{abstract}
Purpose - The difficulty of attributing subject to editorial cartoons for indexing purposes exists both for traditional paper-based cartoon formats and for digitized or born-digital cartoons. This paper presents a selective review of literature on indexing editorial cartoons and the associated challenges.

Design/methodology/approach - A gap exists in published research on indexing collections of editorial cartoons for online search and retrieval. This paper presents a review of selected works that specifically address the topic of editorial cartoon indexing within a wider context of research that addresses image indexing, subject analysis and indexing challenges more generally. Works that address the interpretation of cartoons by readers and how readers respond to information communicated by editorial cartoons are also considered.

Findings - Cartoon controversies in transnational and multicultural contexts, experienced through the international news media since 2000, have dramatically increased research attention and publications in this area. Profound changes in media publication since the advent of the Internet have had an impact on editorial cartoonists and cartoon publishing. Subject indexing of editorial cartoons remains a challenge.

Research limitations/implications - The potential for large indexed cartoon collections to be data-mined for topic modeling for research in the social sciences points to the need for indexers of cartoon collections to improve metadata standards and structures to allow improved access to cartoon metadata for computational analysis.

Originality/value - This paper places discussion of the technical challenges facing indexers of editorial cartoons within a broader context of discussions about the nature and future of editorial cartooning in rapidly changing media and publishing environments.
\end{abstract}

Keywords Editorial cartoon indexing, Image indexing, Political cartoon indexing, Subject analysis Paper type Literature review

\section{Introduction - editorial cartoons}

Editorial cartoons are generally defined as cartoons that contain subject matter and commentary on political or social issues (Landbeck, 2002; El Refaie, 2009; Schilperoord and Maes, 2009). They are more likely to be composed as single frames than strips, although some editorial cartoons such as Garry Trudeau's Doonesbury (The Washington Post, 2019) are produced as strips (Chen et al., 2017). Increasingly editorial cartoons are created entirely digitally rather than in the traditional graphic materials of ink, pencil, paper and pigment. While the terms "editorial cartoon" and "political cartoon" are both used to describe cartoons of a political nature, the term "editorial cartoon" can be considered a slightly more encompassing term, which allows for published cartoons about social and cultural issues to be considered together with political cartoons (Landbeck, 2002). However, in the Thesaurus for Graphic Materials, the broader term for both "Editorial cartoons" and "Political cartoons" is "Cartoons (Commentary)" (Library of Congress, 2020a). An attempt to identify genres and subgenres of editorial cartoons has been discussed by Pedrazzini and Scheuer (2018).

Across the visual art media, digitization of traditional visual art forms (e.g. paintings, drawings, prints and photographs) and the increasing production of born-digital art forms

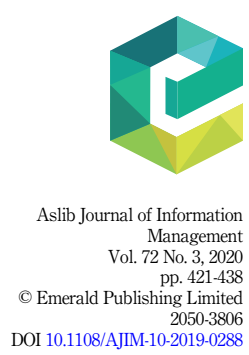


AJIM

72,3

422

(e.g. photographs and cartoons) have led to the development of large digital image libraries. This, in turn, has highlighted the need for improved indexing techniques to facilitate access by remote users (Zhou et al., 2017). Traditionally, indexing methods for visual materials have been designed to assist specialist audiences or tailored for particular kinds of collections (Jörgensen et al., 2001). Such methods often utilize thesauri such as the Thesaurus for Graphic Materials (Library of Congress, 2020b) and the Art and Architecture Thesaurus (Getty Research Institute, 2017) within metadata structures such as VRA Core (Library of Congress, 2018) and the Dublin Core Metadata Element Set (Dublin Core Metadata Initiative, 2020).

Mello (1998) provided a useful overview of editorial cartooning as it was at the end of the 20th century, pointing out that "editorial cartoonists give meaning to facts and help to construct social reality, but exactly how they do this, what messages are embedded in their work, and the impacts they have are not completely understood" (p. 379). Such interpretational challenges are illustrated by born-digital draft versions of a cartoon by Mark Winter dealing with the performance of minor political parties in results from New Zealand's 2014 General Election, held by the New Zealand Cartoon and Comic Archive (NZCCA) at the National Library of New Zealand. These cartoons are especially difficult to interpret without the benefit of specific information about the political events referred to in the images (Figure 1).

As Chen, Phiddian, and Stewart (2017) put it, studies on aspects of institutional collecting, preserving, indexing, digitizing and displaying political cartoons are "almost non-existent" (p. 147), though they cite Hackbart-Dean (1997) and Landbeck (2013) as exceptions. HackbartDean (1997) and Landbeck (2013) themselves identify this literature gap, as does Wu (2013). The work of Johnston and Köentges (2016) on the usability of metadata for the New Zealand Cartoon Archive at the Alexander Turnbull Library, National Library of New Zealand

Figure 1 .

"Pop, boom bang": digital cartoon by Chicane (Mark Winter) published in the Southland Times, September 22, 2014, following New Zealand's 2014 General Election; New Zealand Cartoon and Comic Archive, Alexander Turnbull Library, National Library of New Zealand. Image copyright Mark Winter. Permission to reproduce courtesy of Mark Winter

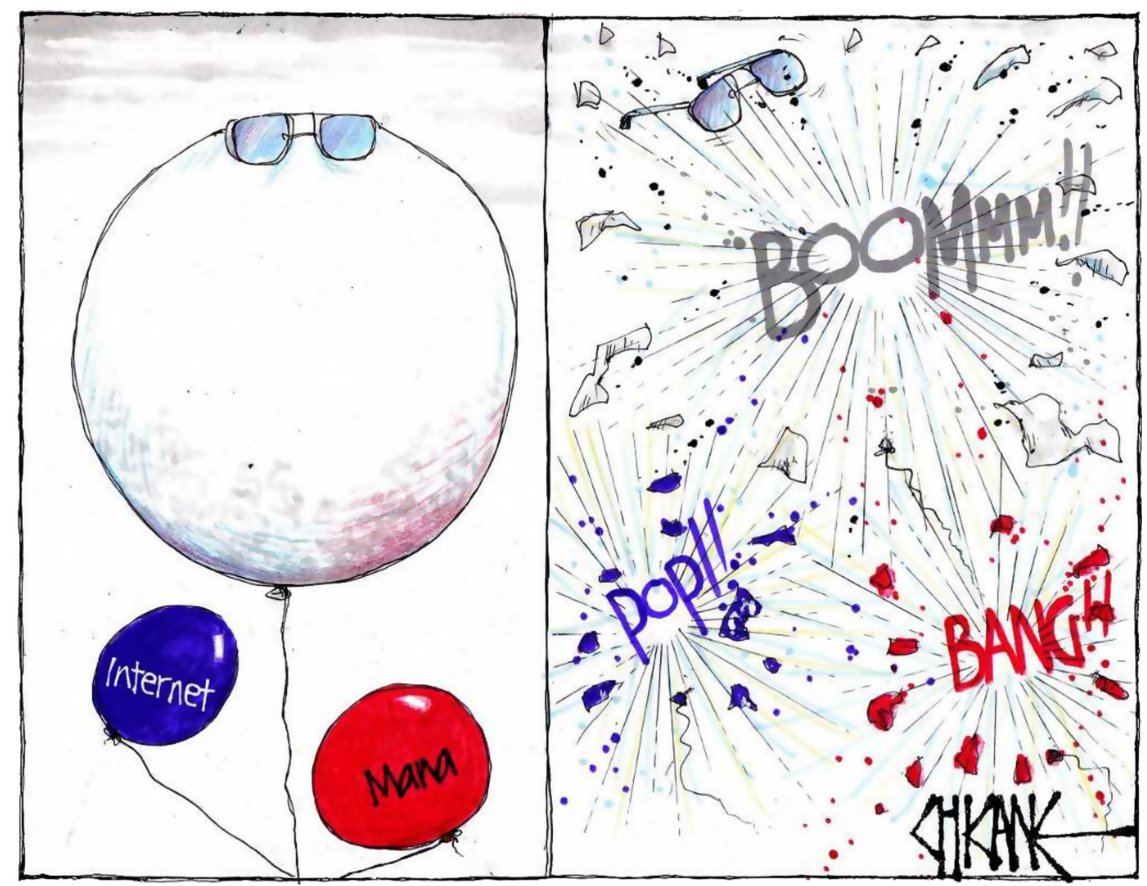


suggests that there is little published research about computational topic modeling using data sourced from cartoons.

\section{Research objective and scope of review}

This review aims to address the gap identified in previous related works, although the coverage is intended to be selective and indicative rather than comprehensive. It attempts to present a snapshot of selected research that addresses the topic of editorial cartoon indexing within a wider context of publications, including those that address image indexing, subject analysis and indexing challenges more generally. Works that address the interpretation of cartoons by readers and how readers respond to information communicated by editorial cartoons are also considered. The review focuses on four perspectives of approach toward the subject of indexing editorial cartoons with the following objectives:

(1) To highlight literature relevant to the wider theoretical context of image analysis for descriptive and interpretive purposes, of which cartoon indexing is a specialized field.

(2) To select and present recent studies that relate to national, transnational, multinational and multicultural aspects of editorial cartoons, including publications that discuss the dynamic and rapidly changing international environment in which editorial cartoonists have worked since the year 2000, with relevance to the topic of reader responses to editorial cartoons. Inclusion of these resources is intended to assist awareness of the wider social, cultural and political factors, which indexers of editorial cartoon collections ought to highlight and reflect in their indexing work.

(3) To draw attention to resources that deal specifically with the challenges of indexing of editorial cartoons for online search and retrieval. This is a narrower field of research, which nevertheless has major implications for the wide range of academic disciplines, which draw on data contained in editorial cartoons from time to time.

In selecting resources that are of special relevance to indexing editorial cartoons, it has been necessary to exclude publications that deal more specifically with related genres and formats such as comics, graphic novels, zines, photography and moving image. Resources that deal with the challenges of indexing such materials have only been included where the indexing principles they outline apply more or less equally to indexing editorial cartoons.

The search strategies utilized were relatively simple, due to the comparatively limited amount of published research on editorial cartoons available across multiple academic disciplines and the very limited amount of published research specifically about indexing editorial cartoon collections. It was found that in the process of searching databases of academic publications for research on editorial cartoons, the most productive search strategies for material relevant to this project were very simple, including the following:

More complex searches (but not very much more) such as [All: "editorial cartoons"] AND indexing] were found to produce very limited numbers of relevant results, suggesting the specialized nature of the core research topic.

Searches were conducted across a wide range of databases of academic publications, including Communication and Mass Media Complete, EBSCOhost, Emerald, Encyclopedia of Library and Information Science (Fourth Edition), JSTOR, ProQuest and Taylor and Francis Online. Google Scholar was also used to identify relevant material. Materials identified in results returned by Google Scholar were then re-searched for in databases, enabling more precise, accessible results. Identified resources were assessed individually for relevance. Keyword searches of the term "cartoon" were applied to each resource to help determine inclusion or exclusion. 
AJIM 72,3

More recent studies into indexing techniques for visual materials have focused on semantic approaches to identifying image content, with the aim of aiding computerized retrieval of data relating to content as well as format. This area of research has seen a convergence of approaches from the fields of library and information studies and computer science around the concept of content-based retrieval (Enser et al., 2007; Zhou et al., 2017). Much of the research in this area has been focused around the challenges of identifying subjects in visual images according to predefined, hierarchical classification structures that attempt to identify levels of meaning in the visual arts. The creation of descriptive metadata for indexing and retrieval of cartoon collections is especially challenging, due to the inherent difficulties for the indexer in correctly attributing subject and identifying implied meaning in individual cartoons (Chapple-Sokol, 1996; Landbeck, 2002; Wu, 2013).

Scholars in the field of image analysis have frequently drawn on Panofsky's three-level hierarchy of iconological significance (Panofsky, 1939, 1955) as the basis of efforts to devise controlled hierarchies of subject categories for image indexes (e.g. Shatford, 1986; Jörgensen, 1995; Landbeck, 2002; Wu, 2013). The emergence of social tagging as a democratized, natural language-based, nonhierarchical method of generating indexing terms has challenged the hierarchical methodologies devised by professional indexers (Rafferty and Hidderley, 2005; Jörgensen, 2007; Rafferty, 2011; Stvilia et al., 2012). The advent of tagging has stimulated debate about the relative advantages of user-generated tags versus professional image indexing and the use of controlled authority versus natural language indexing terms (Baker, 2013a).

\section{Editorial cartoon studies}

More recently, Chen et al. (2017) state that while an extensive literature on editorial cartoons exists across a wide variety of different academic disciplines, very few attempts have been made to survey this literature comprehensively, to "map the field" of academic editorial cartoon studies (p. 125).

Editorial cartoons are frequently discussed in studies of visual literacy, but opinion is divided about the extent to which their implied messages can be decoded and understood by readers due to cartoons' reliance on visual metaphor to convey meaning. The combinations of text and visual images that are commonly found in editorial cartoons tend to increase the range and complexity of their implied metaphorical meanings and their interpretation by readers. Mello (1998) notes that editorial cartoons are designed for quick consumption. Archived editorial cartoons become harder to interpret as time goes by Landbeck (2002). Several classic studies have suggested that the intended implied meaning of editorial cartoons may not be correctly decoded and understood by many readers (Carl, 1968; Bedient and Moore, 1985; El Refaie, 2009; El Refaie; Hörschelmann, 2010).

While El Refaie's research has shown that editorial cartoons can be misinterpreted by both school students and university-educated readers (E1 Refaie; Hörschelmann, 2010), McGurk (2016) strongly promotes the use of editorial cartoons in the classroom. Shaw (2007) draws attention to the political cartoon holdings of the British Library and their usefulness to students of the development of magazines and newspapers. Schnakenberg (2010) provides a useful summary of the pros and cons of teaching German history through cartoons. Caswell (2004) looks at the topic of war in American editorial cartoons. Eko (2010) shows that throughout the African continent "cartoons and caricatures have become the critical narrative device of choice" (p. 68) in the media. Hammett and Mather (2011) have shown that editorial cartoons are valuable aids for teaching political geography to students in South Africa. The NZCCA collection at the National Library of New Zealand has been drawn on extensively for illustrations to published research on aspects of New Zealand's political and social history and more recently, the country's history of race relations (Diamond, 2018). Library and Archives Canada provides online educational resources providing thematic access to editorial cartoons about Canadian Federation Library and Archives Canada (2020). 
As cartoonists frequently utilize a combination of graphic image and text to convey meaning, the academic discourse about them frequently draws on studies of metaphor, rhetoric and iconology, sourced from a variety of disciplines. The works of 20th century linguistic and literary and media theorists, including Bakhtin, Saussure, Barthes, McLuhan and Burke are often cited by writers analyzing the cognitive processes involved in reading and decoding editorial cartoons. Bostdorff (1987) discusses a Burkean approach to interpreting editorial cartoons. Morris (1993) examines visual rhetoric in editorial cartoons through a structuralist lens. A neoclassical approach that locates the visual rhetoric of cartoons within the classical tradition of rhetorical argument can also be helpful in interpreting editorial cartoons (Kenney, 2002). Important studies of rhetoric in editorial cartoons include Medhurst and DeSousa (1981) and DeSousa and Medhurst (1982). Drawing on academic studies of formal rhetoric, these authors propose a basic taxonomy for classifying the persuasive means by which cartoonists convey their intended messages to the reader. Their proposed taxonomy of rhetorical devices found in cartoons includes rhetorical invention, graphic disposition, rhetorical style, the evocation of memory and presentation as delivery, where each type of rhetorical device is illustrated by a range of cartoon exemplars Medhurst and DeSousa (1981).

Many studies have been published on metaphors employed in editorial cartoons on specific news topics. For example, Bounegru and Forceville (2011) studied metaphors in cartoons about the global financial crisis. In terms of the theory of metaphor as it applies to editorial cartoons, a frequently cited resource is Lakoff and Johnson's influential book, Metaphors We Live By, which suggests that the human cognitive system is structured metaphorically (Lakoff and Johnson, 1980). This work discusses the implications of common metaphors such as "time is money," together with associated meanings that metaphors sometimes conveniently obscure (Lakoff and Johnson, 1980, p. 7). While the "time is money" example is a fairly basic, concrete one, editorial cartoons often make use of more complex, multimodal metaphors to convey the meanings intended by their authors. In a study of Austrian newspaper cartoons, El Refaie (2003) observed that while interplay between verbal and visual metaphor was often present, the verbal and visual modes of metaphor did not operate analogously and that cartoons must be studied in their sociopolitical context. Profound differences exist between literal and metaphorical thought, as expressed in a variety of verbal and visual modes. Moreover, "every individual reader or viewer is likely to bring his or her own experiences and assumptions to the interpretation process" (p. 77). Schilperoord and Maes (2009) meanwhile argue that full interpretation of editorial cartoons requires the viewer to combine two distinct types of reasoning, schematic and taxonomic.

The concepts of modality and multimodality are valuable in analyzing meaning in all types of visual images. Rafferty (2011) discusses multimodality and its relationship to interpretation in the context of user tagging of website images. Lin and Chiang (2015) discuss multimodal fusion in cartoons addressing US beef imports into Taiwan, for instance. However, researchers have pointed out that the full spectrum of multimodal meanings intended by cartoonists may not necessarily be understood by viewers if they do not have all of the necessary background knowledge to inform their individual interpretation (Schilperoord and Maes, 2009). Increasing political sophistication and public awareness of political strategy around election campaigns may also account for changes in depictions and humor found in editorial cartoons published in the United States since 1960 (Kline and Hill, 2010).

The metaphorical approach is useful for analysts of editorial cartoons in all disciplines. Sŏ;rm and Steen (2013) discuss editorial cartoons among other types of visual art materials employing visual metaphor. From the opposite perspective, editorial cartoons can also be useful in the study of metaphorical thinking and how it develops. Domínguez (2015) discusses an evolutionary model of metaphor development using published cartoons about the Charlie Hebdo cartoonist murders. In this study, cartoons expressing the relatively simple metaphors "pencil is a weapon," "pencil is a cartoonist" and "pencil is freedom" are examined. 
AJIM 72,3

A similar rhetorical analysis of two published cartoons created in response to the Charlie Hebdo murders is discussed by Bezanzon (2017). Olson and Olson (2004) meanwhile use editorial cartoons as examples to illustrate ways in which readers perceive irony. The concepts of "aboutness" and "ofness" (Hutchins, 1977; Shatford, 1986) have been useful to scholars researching the design of metadata schemas for visual materials. These concepts are especially useful in the analysis and decoding of editorial cartoons. Thus, a cartoon can appear, for instance, to be a picture "of" an orange lavatory but be intended by Guardian cartoonist Steve Bell to be "about” US President Donald Trump (Bell, 2016).

In other studies, Lan and Zuo (2016) explore aspects of pictorial-verbal metaphor in Chinese editorial cartoons on food safety, sourced from the website http://cartoon.chinadaily.com.cn, and Ulubeyli et al. (2015) conduct a semiotic analysis of workplace health and safety cartoons from several countries. In an examination of editorial cartoons concerning the Referendum on the European Constitution held in France in 2005, Marín-Arrese (2008) compares and contrasts visual perceptions and representations in cartoons published in the English and Spanish press in order to explore the cognitive mechanisms involved in constructing meaning.

\section{Cartoon controversies}

Notwithstanding the many questions of interpretation that editorial cartoons present for their viewers, many editorial cartoons have the potential to polarize viewers and opinions and at times, provoke extreme or unexpected responses. The former editor of The New York Times and long-time editor of The Nation, Navasky (2013), provides a brilliant summary of the history of political cartooning from its origins in the Italian Renaissance to the present. The commentary includes sections on the cartoon as content, the cartoon as image and the cartoon as stimulus, as well as a useful section on caricature. About 31 internationally influential cartoonists are profiled in individual chapters, including the New Zealand-born cartoonist David Low (1889-1963), acknowledged as "the twentieth century's greatest caricaturist" (p. 113). A fascinating timeline at the end of the book presents a chronological selection of events from 1831 to 2012 in which cartoonists were charged with offenses or subject to violent attack for their works.

Benson (1998) demonstrated how the unusual license accorded to Low by his publisher Lord Beaverbrook allowed the cartoonist an extraordinary freedom of expression. Low's status as both artist and influential journalist remains of interest to contemporary media commentators (Hampton, 2013). Dramatic changes in traditional news media publishing brought about by the advent of the Internet have impacted on editorial cartoonists and their work, with many former staff positions being disestablished by publishers around the world and many cartoonists becoming independent contractors (Mello, 2007). Such changes have altered the traditionally close relationship between editorial cartoonists, editors and publishers.

In the 21st century, the role of editorial cartoonists is increasingly at the center of debate about press freedom. Since the $9 / 11$ terrorist attacks in the year 2000 , the traditionally satirical role of editorial cartoonists in the international news media has come under intense pressure and scrutiny from many directions. In the wake of the 9/11 attacks, some US-based commentators suggested editorial cartooning was in decline, partly because cartoonists found it challenging to express their natural inclination to negative satire in the context of increasing nationalism (Katz, 2004; Oliphant, 2004). Editorial cartoons and cartoonists have been at the center of international controversies, for example, the Danish Jyllands-Posten Muhammad cartoon controversy of 2005. Edwards (2007) noted that although editorial cartoonists were once treated as celebrities, they no longer enjoyed the same respect. Nevertheless, the media prominence of cartoon controversies has stimulated academic studies of the mechanisms by which satire operates in the popular media (LaMarre et al, 2014). Some commentators have suggested that editorial cartoons can play a "healing" role in the recovery of communities from terrorist attacks (Berkowitz, 2017), while others have suggested that while editorial cartooning may not be in decline, it must take place within a rapidly changing media environment 
(Danjoux, 2007). Against this dynamic background, the editorial independence of cartoonists

has increasing been questioned in the context of press freedom (Dalgaard and Dalgaard, 2006; Berkowitz and Eko, 2007; Veninga, 2016). Berkowitz and Eko (2007) noted that while issues of religious freedom of expression and freedom of speech were frequently associated by the international media with the Jyllands-Posten Muhammad cartoon controversy, the controversy came to represent wider issues such as beliefs about national identity, core cultural values, immigration and multiculturalism. In their analysis of the Jyllands-Posten Muhammad cartoon controversy, Codina and Rodríguez-Virgili (2007) drew attention to the global aspects of press actions in the context of cultural coexistence.

As recently as 2018, a New Zealand cartoonist and his publisher have been the subject of legal action regarding implied and inferred racial prejudice in their editorial cartoons (Gattey, 2018). Around the world, there are many editorial cartoonists who are imprisoned or have been threatened with imprisonment by oppressive regimes, for instance, Zunar of Malaysia (Soon, 2011). This has led to the establishment of the Cartoonists' Rights Network International, an organization that aims to help cartoonists safeguard their freedoms of expression. It has been suggested that politicians are able to suppress negative criticism more effectively if they are able to frame editorial cartoons as attacks on a whole nation rather than on an individual (Lamb, 2007).

Whether or not editorial cartooning is in fact in decline, it continues to attract attention and dialogue. Increasingly this attention is focused on transnational and multicultural contexts (Lægaard, 2007). The Jyllands-Posten Muhammad cartoon controversy of 2005 has stimulated studies of editorial cartoons in several academic fields and the publication of research investigating multicultural and transnational responses to editorial cartoons (e.g. Lægaard, 2007, 2010; Y1lmaz, 2011). The fatal shooting of editorial cartoonists, staff and police at the Paris offices of the satirical Charlie Hebdo journal in 2015 highlighted the sometimes dangerous conditions under which editorial cartoonists may have to work. Visual framing by international media in response to the Charlie Hebdo shootings helped to communicate and construct narratives about press freedom (Gustafson and Kenix, 2016) and further stimulated research into the multinational aspects of editorial cartooning and reader responses (Khan et al., 2019; Mackay and Horning, 2017).

Constantinou (2018) looks at the complex cross-linguistic and translational aspects of narratives constructed in the international media concerning the Charlie Hebdo attacks. The ability of cartoon images to bypass linguistic and national barriers may be consciously used by political regimes to try to influence and set global and transnational political agendas (Müller et al., 2009). For Sanadjian (2015), the Charlie Hebdo attacks emphasized a profound change in the traditional roles of author and reader, with the author's role becoming increasingly restricted and the role of the diverse readership becoming correspondingly more autonomous.

\section{Indexing editorial cartoons for online search and retrieval}

\subsection{Editorial cartoon searching}

These days, large collections of digital cartoons can also be accessed via the websites of news media publishers such as The New York Times, The Guardian and China Daily. The American Association of Editorial Cartoonists maintains a website providing access to archived digital cartoons, in addition to news and educational resources. Increasingly, editorial cartoonists also maintain their websites, giving access to archived digital cartoons. Extensive collections of editorial cartoons in all formats have been built up for political and social research purposes by universities as well, such as the University of Kent (The British Cartoon Archive) and the Ohio State University (The Billy Ireland Cartoon Library and Museum). The British Cartoon Archive and the Billy Ireland Cartoon Library and Museum have been energetic in publishing guides to searching their collections, for instance, in a variety of formats including Web-based platforms such as blogs. Baines (2018a, 2018b); 
AJIM 72,3

428

provides a number of tips in blog posts on searching for archival materials and special collections at the University of Kent, including the British Cartoon Archive collections. Examples of tips include thinking around the research area, differentiating between published and unpublished materials, searching by keyword and authority terms such as artist, place and date, using advanced search functions and checking copyright status.

National libraries have also developed large research collections of editorial cartoons, including the Library of Congress, Library and Archives Canada and the National Library of New Zealand (NZCCA). The practical challenges of managing large collections of editorial cartoons include the large volume of works produced by cartoonists, who are often required by their editors to produce finished works regularly. In archival collections, cartoons created in traditional formats require the technical support of controlled environmental conditions to maintain. Archival digital cartoon collecting also requires state-of-the-art digital curation and preservation resources, including the employment of professional digital archivists and the use of digital archive systems for long-term preservation of digital materials (Love, 2018).

Notwithstanding anecdotal accounts of how cartoon collections are useful for research, for example, Shaw (2007): "American cartoons offer a rich resource for the study of American culture and the development of magazines and newspapers," this literature review has found little published research on the ways in which remote users consult indexed cartoon collections. This may well be a fruitful area for further research.

The challenges of cartoon interpretation confronted by general readers impact on the practice of indexing cartoons for access in electronic catalogues of formed cartoon collections. In their study of image attributes perceived to be important for identification as access points for retrieval, Choi and Rasmussen (2003) include cartoons among types of images retrieved by user queries for images relating to American history. Despite the large numbers of editorial cartoons that are now searchable online, Wu (2013) states that "many readers have seen cartoons in newspapers or on the Web, but few have searched them in a cartoon database" (p. 283). Landbeck (2013) compared user responses to editorial cartoons in the context of both user tagging and querying behaviors. Zhang et al. (2013) designed a search system for a small collection of historical political cartoons based on the assumption that "the search engine should serve historians" (Zhang et al., 2013). On this basis, they included search engine design features intended to maximize users' ability to explore by supporting both serendipitous and focused searching.

Farmer (2015) examines information architecture in relation to indexing for the comic arts, including graphic novels and Japanese manga, and analyzing such materials at the level of component elements such as text bubbles, strips, panels and gutter comments. The challenges of describing editorial cartoons can be thought of as a special subset of these broader sets of image description challenges for indexers. Little consideration has been given in the literature, however, to whether it might be possible to develop a story-based system for indexing images (Rafferty and Albinfalah, 2014). Benson (2015) discusses aspects of describing relationships between entities such as people, places and things, as expressed in photographs and other images including cartoons, for the purposes of creating machinereadable collection records.

Many GLAM sector organizations (galleries, libraries, archives and museums) maintain exportable data sets for collection records, formatted in schemas such as Encoded Archival Description (EAD) (Library of Congress, 2020a), available for downloading by external users. The emerging techniques of computational topic modeling in the social sciences have raised the potential for exported metadata from editorial cartoon indexes to be "data-mined" to help shed light on historical, social and political trends (Johnston and Köntges, 2016). Baker (2013b, May 16) discusses the results of an experimental analysis performed on an export of .xml metadata from the British Cartoon Archive, using topic-modeling techniques to interrogate the metadata for topic trends. Interestingly, metadata created in the 1960s and 
1970s was found to be richest in this study, with the most interesting data being found in the Title and Subject fields. Köntges (2016) discusses how topic-modeling techniques applied first to data sets relating to editorial cartoons on earthquakes in the National Library of New Zealand were subsequently applied to use cases at the Open Philology Project, University of Leipzig and the Roshan Institute for Persian Studies at the University of Maryland. These use cases adapted topic modeling for research on Ancient Greek, Latin, Classical Arabic and Persian language corpora, demonstrating that the techniques were effective for multilinguistic humanities research, and suggesting that topic modeling could be more widely utilized by digital humanities researchers, provided the techniques are used to help answer specific research questions.

\subsection{Editorial cartoon indexing}

Ambiguities inherent in cartoons present challenges to natural language understanding by computers (Mazlack and Paz, 1983). Hackbart-Dean (1997) provided a detailed case study of a project to identify, preserve and provide item-level cataloguing of the Clifford "Baldy" Baldowski Collection of original editorial cartoon artworks at the Richard B. Russell Library for Political Research and Studies. The author noted that assigning subjects to historical editorial cartoons was made complicated by changing opinions, the relevance of subject headings and the time required to cross-reference original cartoon artworks to the specific newspaper editions they were published in, to ascertain context (Hackbart-Dean, 1997). Many of the basic challenges and solutions for electronic indexing of editorial cartoons were outlined by Bovey $(1992 ; 1995 ; 2003)$ during the development of an online catalogue for the extensive cartoon archive at the University of Kent (now the British Cartoon Archive). Landbeck's (2012) summary of the "state of the art" of providing online access to editorial cartoons remains highly relevant.

Over the past two decades, there has been an explosive growth in the literature on search and retrieval of images indexed in electronic catalogues and databases (Zhou et al., 2017). However, within this dynamic, rapidly growing field of research, there are relatively few published studies that focus specifically on indexing editorial cartoons (Landbeck, 2013; Wu, 2013; Chen et al., 2017). The intellectual challenges of indexing editorial cartoons are complex (Chapple-Sokol, 1996). The difficulty of attributing subject to editorial cartoons for indexing purposes exists both for traditional paper-based cartoon formats and for digitized or borndigital cartoons. Despite the much-acknowledged paucity of published research on editorial cartoon indexing, there has been some outstanding work done on the topic nevertheless, notably by Chapple-Sokol (1996) and Landbeck (2002, 2013).

Landbeck (2002) noted that "the categorization and organization of political cartoons has historically been a non-starter. Lack of resources and lack of interest have been cited as reasons for the exclusion of these works from the historical record" (p. 7). For the purposes of the research, Landbeck used the term "editorial cartoon" as a more encompassing term than "political cartoon." His enquiry focused on two questions, whether it is possible to define categories for classifying cartoons to enable research by users, and whether there is a research demand for such classification. To test these questions, a three-part study was conducted using 12 voluntary participants who were asked to look at and interpret a range of editorial cartoons from different periods. Landbeck (2008) outlines three basic cataloguing needs for editorial cartoons indexed in electronic databases; bibliographic, descriptive and subject. Bibliographic needs for editorial cartoons have much in common with those of documents; subject and context are very challenging to describe. A metadata schema is useful for describing editorial cartoons, to allow for wider, faster and more effective indexing for retrieval.

Dyer (2014) describes a project to catalogue a group of some 300 original cartoons and artworks by the editorial cartoonist Charles Sykes, at the Virginia Commonwealth University 
AJIM 72,3

Libraries. Many of these cartoons were published in the Evening Public Ledger (Philadelphia) in the 1930s and 1940s. Challenges encountered by indexers in cataloguing this collection included the lack of earlier cataloguing, lack of accurate date information, difficulties in identifying subject matter, the need for background research to determine accurate Library of Congress name and subject headings and uncertainty around whether characters depicted in the cartoons represented real people or fictional, symbolic identities created by the artist.

Extrapolating from the findings from the Sykes cartoons indexing project, Dyer identifies several categories of challenges for cartoon indexers. Image cataloguing challenges include problems of "aboutness" and "ofness" and the accurate interpretation of intended visual metaphor. Challenges specific to handling cartoons include lack of available data relating to the cultural context of editorial cartoons, especially from earlier time periods, and this was compounded in the absence of available subject experts for the relevant periods in history. The personal artistic style, conventions and innovations of individual cartoonists also have an impact on the ability of later cataloguers to identify subjects in their works, particularly when it comes to people, who may be difficult to recognize. Subjects of a more ephemeral, time-specific nature, which have been caricatured by cartoonists in daily papers, may be more difficult to identify because of the fleeting nature of their topicality at the time of publication and lack of relevant contextual documentation. Finally, Dyer (2014) notes that the intricate relationships between text and image in editorial cartoons require that accurate capture of captions and other text elements and provision of keyword access to these elements should be prioritized in cataloguing and indexing such items.

Dyer (2014) suggested some solutions including matching original cartoon artworks with their published versions, referencing front pages of relevant newspapers to determine broader contemporary news context and the provision of additional indexing fields (e.g. within a qualified Dublin Core metadata structure to enable more precise subject searches for indexed cartoons).

\subsection{Controlled vocabulary, free-text and user-tagging approaches to editorial cartoon indexing}

A detailed study carried out by Landbeck (2013) compared terms and phases used by two sample populations to describe a group of recent editorial cartoons by Pulitzer Prize-winning cartoonists. One sample user population was drawn from academics considered likely to provide detailed descriptions of the cartoons. The other population was drawn from nondegree-qualified participants. Participants were asked to provide descriptive terms in a tagging environment and subsequently asked to provide terms for searching for cartoons in a query environment. Descriptive terms supplied by the two groups were sorted according to Jörgensen's 12 classes of image description. It was found that while the terms could be fitted into the 12 classes, users described editorial cartoons in significantly different ways to other types of images. Jörgensen's Abstract Concepts class dominated descriptions and searches. The class viewer reactions also played a large role in descriptions supplied by users in the experiment. Major differences in tagging behavior existed among participants with different education levels and in querying behavior among participants with different genders and political views. Results were discussed with professional image indexers and cartoonists, and it was found that the information could potentially be helpful for indexing and retrieval of editorial cartoons.

As noted earlier, the work of Panofsky $(1939,1955)$ on identifying levels of meaning in the visual arts has been extremely influential on research by scholars in the field of library and information studies. Research aimed at devising classification and metadata schemas for the description and indexing of visual materials, including editorial cartoons, frequently cites Panofsky's three-level system of iconological significance (Shatford, 1986; Enser, 1995; Jörgensen, 1995; Landbeck, 2002; Rafferty, 2011; Winget, 2009; Wu, 2013). Some scholars 
have, however, criticized Panofsky's schema as being inherently hierarchical and Eurocentric, having the potential to be inappropriate or disadvantaging when applied to descriptions of non-European cultural materials including editorial cartoons that reflect the sociocultural aspects of a non-European context (Winget, 2009).

Building on Panofsky's basic three-tier hierarchy, more elaborate classification schemes for identifying levels of meaning in images have been proposed. Rafferty and Hidderley (2005) propose several multilevel models for the classification of levels of meaning in multimedia materials. Jörgensen et al. (2001) propose a ten-level "pyramid" of image attributes, featuring four syntactical and six semantic levels of meaning, based on Jörgensen's (1995) 12-level classification model for levels of meaning. Wu (2013) proposes an adaptation of Panofsky's three-level model, including sublevel data fields, designed specifically for the description of born-digital editorial cartoons. Wu notes that "there is no standard metadata scheme for describing digital, political cartoons" (Wu, 2013, p. 287).

Within public collecting institutions such as the British Cartoon Archive, it has formerly been the norm for professional indexers to do the work of indexing editorial cartoons (Newton, 1999; Seymour-Ure, 2001; Baker, 2013a). In recent years, however, indexing projects have been initiated utilizing crowdsourcing, in which nonprofessional volunteers contribute metadata to indexing records for editorial cartoon collections (Baker, 2013a). Many public collecting organizations around the world provide options for tagging online catalogue entries, whereby users are encouraged to annotate entries for indexed items with noncontrolled, natural language subject terms of their own choice. Over time, large "folksonomies" of tag terms develop through the contributions of individual users (Stvilia et al., 2012). Folksonomies can be presented online in the form of word clouds, which graphically show the relative popularity of tag terms in relation to indexed items. Through this process, user-generated indexing has been suggested as a democratized product, rather than a hierarchical, authoritative one. While the extent to which social tagging can add value to image indexing has been questioned by some (Stvilia et al., 2012; Baker, 2013a), as Wu (2013) has demonstrated, there can be substantial variability of editorial cartoon indexing between professional indexers, even when they are using controlled vocabularies and operating identical business rules. Zhang et al. (2013) conducted a project to crowdsource the generation of metadata for a small group of cartoons published by a single Dutch cartoonist between 1937 and 1942, digitized by the National Library of the Netherlands. Online volunteers were provided with an online survey modeled on questions that historians would typically ask about a cartoon. These were presented as 31 questions in eight stages. Cartoons were randomly assigned to volunteers, and answers were validated by the project organizers. Interestingly, the authors do not report variations between volunteer responses to the questions in this study.

The relative mix of controlled vocabulary versus free-text components of records for visual and digital materials collection has received considerable attention in recent years. Baker (2013b) found that the semantic richness of collection records compiled by professional indexers working with the cartoon collections of the University of Kent was particularly useful for contemporary computerized data-mining research on social science topics. In collection-level metadata, the use of free-text description fields in combination with controlled vocabulary fields can provide more accuracy and completeness in the representation of subjects and object types than specified fields alone (Zavalina et al., 2009). At the Alexander Turnbull Library, National Library of New Zealand, born-digital cartoons are received regularly from editorial cartoonists. Examples are the born-digital draft versions of a cartoon by Mark Winter in the NZCCA mentioned earlier.

Cartoons assigned to the NZCCA are catalogued using Encoded Archival Description standards. A detailed in-house cataloguing manual provides guidance for staff on mandatory fields and default field values. Titles are taken from the work itself wherever possible, and titles supplied by artists are preferred to titles supplied in-house. Free-text scope and contents 
AJIM 72,3

432
Figure 2.

National Library of New Zealand public online catalogue record metadata for Mark Winter, "Pop, boom bang," digital cartoons, 2014, catalogued using Encoded Archival Description, controlled indexing terms and free-text scope and contents notes.Permission to reproduce courtesy of National Library of New Zealand notes are usually generic due to the volume of born-digital cartoons received and the time it takes to provide scant catalogue records for them (Figure 2). The authors' practical experience in administering this collection tends to support Dyer's (2014) observation that "having the date of publication would provide important information about the cartoons, which in turn would assist in cataloguing the collection" (p. 287). In the case of born-digital cartoons received in bulk from cartoonists for the NZCCA, it is not always clear which version of an image has been published, if at all, as cartoonists often provide editors with multiple versions of a cartoon image on a particular date, covering a particular subject. In such instances the library's practice may include noting the following statements in the EADOtherDescriptiveData field: "colour and black and white versions available"; "versions with alternative colour grading available"; or "multiple versions of this cartoon are available".

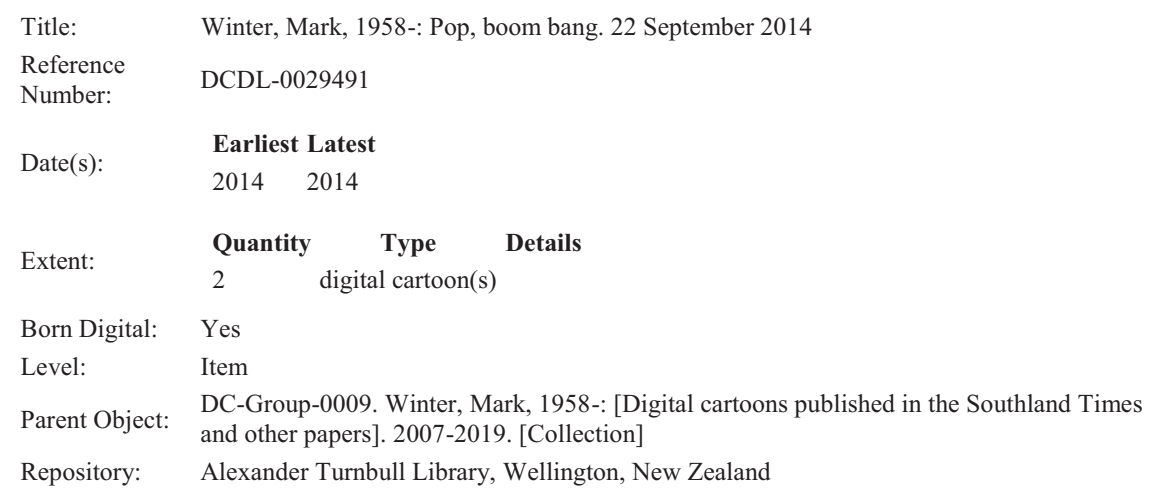

Access and Use

Access Statement: No access restrictions

Use Conditions: $\quad$ Please check copyright

Details

Two frames show three balloons floating and then popping with a bang. One version has text for

Scope and a balloon floating away. The balloons are blue (the Internet Party), red (the Mana Party) and one Contents: large white balloon is wearing sunglasses (Internet Party funder Kim Dotcom). Refers to the poor showing of the Internet-Mana coalition in the 2014 General Election results.

Material

Specific Image files - Jpeg

Details:

Indexing Terms

\begin{tabular}{lll} 
& \multicolumn{1}{c}{ Name } & \multicolumn{1}{c}{ Role } \\
& Internet Party (New Zealand) & Related subject \\
Names: & Mana Party & Related subject \\
& Internet MANA (Political party) & Related subject \\
& Dotcom, Kim, 1974- & Subject \\
& New Zealand. Parliament - Elections, 2014 \\
& Electoral coalitions & \\
Subjects: & Political parties - New Zealand \\
& Novelty balloons & \\
& Works of art & \\
Types of Material: & Digital images & Cartoons (Commentary)
\end{tabular}




\section{Conclusion and implications for research}

The present study suggests that since the year 2000, there has been limited but considerable research on indexing collections of editorial cartoons. The work of Landbeck (2002, 2008, 2012, 2013), Wu (2013) and Johnson and Köntges (2016) has added to this specialized field of indexing studies.

A common theme in the literature is that of the relative values of controlled language versus free-text metadata fields for cartoon description in automated indexing. A parallel debate concerns the relative values of professional indexing versus social tagging for the identification of content in editorial cartoon indexes. The value of free-text, natural language descriptive fields for identifying and making accessible semantic content in editorial cartoons has been highlighted in recent works (Wu, 2013; Johnston and Köntges, 2016), including that of capturing the date of publication of the original cartoons (Dyer, 2014). A useful further work on this topic could be a systematic comparison of metadata schema and standards as applied to editorial cartoon collections in a range of relevant collecting institutions. For example, Landbeck (2013) provides a discussion on the use of various metadata schema and concludes, despite some reservations, that CDWA (Categories for the Description of Works of Art) is "the best one to use when describing editorial cartoons" (p. 61). A detailed analysis of metadata schema and subject authorities implemented in a range of large-scale established cartoon collections around the world could provide useful insights toward best practice for editorial cartoon indexing. Despite recent growth in the literature on cartoon indexing identified by this literature review, it would appear that there is still very little published research available on the ways in which remote users consult indexed cartoon collections, indicating scope for further research into this topic.

The potential for large indexed cartoon collections to be data-mined for topic modeling for research especially in the social sciences points to the urgent need for indexers to improve metadata standards and structures to allow improved access to editorial cartoon metadata for computational analysis. In an increasingly international, linked- and open-data environment, the adoption of application programming interfaces such as the International Image Interoperability Framework - IIIF (Crane, 2017) also has the potential to enable GLAM sector institutions, including image libraries and archives to present image metadata more effectively and to improve interoperability, where desired. Empirical research into these areas would enhance understanding of editorial cartoons indexing and image indexing in general, and their findings and evidence could usefully inform practice.

\section{References}

Baines, J. (2018), "7 top tips for finding Special Collections and Archives material through LibrarySearch", [Blog post], available at: https://blogs.kent.ac.uk/specialcollections/2018/03/05/ 7-top-tips-for-finding-special-collections-archives-material-through-librarysearch/ (accessed 10 October 2019).

Baines, J. (2018), "7 ways to find material in the British Cartoon Archive", [Blog post], available at: https://blogs.kent.ac.uk/specialcollections/2018/03/14/7-ways-to-find-material-in-the-british-cart oon-archive/\# (accessed 10 October 2019).

Baker, J. (2013a), "Does crowdsourcing capture the crowd at its wisest? An interview with Nick Hiley", [Blog post], available at: http://blogs.bl.uk/digital-scholarship/2013/05/does-crowdsourcingcapture-the-crowd-at-its-wisest-an-interview-with-nick-hiley.html (accessed 10 October 2019).

Baker, J. (2013b), “On metadata and cartoons”, [Blog post], available at: http://blogs.bl.uk/digitalscholarship/2013/05/on-metadata-and-cartoons.html (accessed 10 October 2019).

Bedient, D. and Moore, D. (1985), "Student interpretations of political cartoons", Journal of Visual Verbal Languaging, Vol. 5 No. 2, pp. 29-35.

Bell, S. (2016), "Bellworks", available at: http:/www.belltoons.co.uk/bellworks/index.php/leaders/2016/ 4060-101116_TRUMPCRAPPER (accessed 10 October 2019).
Editorial cartoon collections 
Benson, T.S. (1998), Low and Lord Beaverbrook: The Case of a Cartoonist's Autonomy, Unpublished Doctoral thesis, University of Kent, Canterbury.

Benson, A.C. (2015), "Image descriptions and their relational expressions: a review of the literature and the issues", Journal of Documentation, Vol. 71 No. 1, pp. 143-164.

Berkowitz, D. (2017), "Solidarity through the visual: healing images in the brussels terrorism attacks", Mass Communication and Society, Vol. 20 No. 6, pp. 740-762.

Berkowitz, D. and Eko, L. (2007), "Blasphemy as sacred rite/right”, Journalism Studies, Vol. 8 No. 5, pp. 779-797.

Bezanzon, M.E. (2017), "Political cartoons as epideictic: rhetorical analysis of two of the Charlie Hebdo political cartoons", First Amendment Studies, Vol. 51 No. 1, pp. 1-13, doi: 10.1080/21689725.2017. 1301264 .

Bostdorff, D.M. (1987), "Making light of james watt: a burkean approach to the form and attitude of political cartoons", Quarterly Journal of Speech, Vol. 73 No. 1, p. 43.

Bounegru, L. and Forceville, C. (2011), "Metaphors in editorial cartoons representing the global financial crisis", Visual Communication, Vol. 10 No. 2, pp. 209-229.

Bovey, J.D. (1992), "Tools for preparing an online catalogue of cartoon drawings", Program, Vol. 26 No. 1, pp. 39-54.

Bovey, J.D. (1995), "Building a thesaurus for a collection of cartoon drawings", Journal of Information Science, Vol. 21 No. 2, pp. 115-122.

Bovey, J.D. (2003), "Providing Web access to a catalogue of British newspaper cartoons", Program, Vol. 37 No. 1, pp. 16-24.

Carl, L.M. (1968), "Editorial cartoons fail to reach many readers", Journalism and Mass Communication Quarterly, Vol. 45 No. 3, pp. 533-535.

Caswell, L.S. (2004), "Drawing swords: war in American editorial cartoons", American Journalism, Vol. 21 No. 2, pp. 13-45, doi: 10.1080/08821127.2004.10677580.

Chapple-Sokol, A. (1996), “Indexing editorial cartoons”, Special Libraries, Vol. 87 No. 1, pp. 21-31.

Chen, K.W., Phiddian, R. and Stewart, R. (2017), "Towards a discipline of political cartoon studies: mapping the field", in Milner Davis, J. (Ed.), Satire and Politics the Interplay of Heritage and Practice, Palgrave Macmillan, Cham, pp. 125-162.

Choi, Y. and Rasmussen, E.M. (2003), "Searching for images: the analysis of users' queries for image retrieval in American history", Journal of the Association for Information Science and Technology, Vol. 54, pp. 498-511.

Codina, M. and Rodríguez-Virgili, J. (2007), "Journalism for integration: the Muhammad cartoons", Javnost-The Public, Vol. 14 No. 2, pp. 31-46.

Constantinou, M. (2018), “Charlie Hebdo's controversial cartoons in question: stances, translational narratives and identity construction from a cross-linguistic perspective", Social Semiotics, Vol. 29, No. 5, pp. 698-727, doi: 10.1080/10350330.2018.1521356.

Crane, T. (2017), An Introduction to IIIF, Digirati, available at: https://resources.digirati.com/iiif/anintroduction-to-iiif/.

Dalgaard, S. and Dalgaard, K. (2006), "The right to offend", The RUSI Journal, Vol. 151 No. 2, pp. 28-33.

Danjoux, I. (2007), "Reconsidering the decline of the editorial cartoon", PS: Political Science and Politics, Vol. 40 No. 2, pp. 245-248.

DeSousa, M.A. and Medhurst, M.J. (1982), "The editorial cartoon as visual rhetoric: rethinking boss tweed", Journal of Visual Verbal Languaging, Vol. 2 No. 2, pp. 43-52.

Diamond, P. (2018), Savaged to Suit: Māori and Cartooning in New Zealand, New Zealand Cartoon Archive, Wellington.

Domínguez, M. (2015), "On the origin of metaphors”, Metaphor and Symbol, Vol. 30 No. 3, pp. 240-255. 
Dublin Core Metadata Initiative (2020), Dublin Core Metadata Element Set, Version 1.1: reference description, available at: http://dublincore.org/documents/dces/.

Dyer, M. (2014), "Full speed ahead: the challenges of cataloging a historic editorial cartoon collection", Art Documentation: Journal of the Art Libraries Society of North America, Vol. 33, No. 2 (Fall 2014), pp. 279-294.

Edwards, J.L. (2007), "Media history and marginalized form: the editorial cartoon profession considered", Review of Communication, Vol. 7 No. 1, pp. 127-130.

Eko, L. (2010), "The art of criticism: how african cartoons discursively constructed african media realities in the post-cold war era", Critical African Studies, Vol. 2 No. 4, pp. 65-91.

El Refaie, E. (2003), "Understanding visual metaphor: the example of newspaper cartoons", Visual Communication, Vol. 2 No. 1, pp. 75-95.

El Refaie, E. (2009), "Multiliteracies: how readers interpret political cartoons", Visual Communication, Vol. 8 No. 2, pp. 181-205.

El Refaie, E. and Hörschelmann, K. (2010), "Young people's readings of a political cartoon and the concept of multimodal literacy", Discourse: Studies in the Cultural Politics of Education, Vol. 31 No. 2, pp. 195-207.

Enser, P. (1995), "Progress in documentation pictorial information retrieval", Journal of Documentation, Vol. 51 No. 2, pp. 126-170.

Enser, P., Sandom, C., Hare, J., Paul, H. and Lewis, P. (2007), "Facing the reality of semantic image retrieval", Journal of Documentation, Vol. 63 No. 4, pp. 465-481.

Farmer, L.S.J. (2015), "Information architecture and the comic arts: knowledge structure and access", Journal of Visual Literacy, Vol. 34 No. 2, pp. 23-50.

Gattey, M. (2018), Cartoons Don't Breach Human Rights, Court Finds, The Press, available at: https:/www. pressreader.com/new-zealand/the-press/20180213/281638190667406 (accessed 10 October 2019).

Getty Research Institute (2017), Art and Architecture Thesaurus Online, available at: http://www.getty. edu/research/tools/vocabularies/aat/ (accessed 10 October 2019).

Gustafson, K.L. and Kenix, L.J. (2016), "Visually framing press freedom and responsibility of a massacre: photographic and graphic images in Charlie hebdo's newspaper front pages around the world”, Visual Communication Quarterly, Vol. 23 No. 3, pp. 147-160.

Hackbart-Dean, P. (1997), "Comic relief: the processing, preservation, and cataloging of editorial cartoons", Archival Issues, Vol. 22 No. 2, pp. 163-176.

Hammett, D. and Mather, C. (2011), "Beyond decoding: political cartoons in the classroom”, Journal of Geography in Higher Education, Vol. 35 No. 1, pp. 103-119.

Hampton, M. (2013), "The political cartoon as educationalist journalism”, Journalism Studies, Vol. 14 No. 5, pp. 681-697.

Hutchins, W.J. (1977), "The problem of 'aboutness' in document analysis", Journal of Informatics, Vol. 1 No. 1, p. 18.

Johnston, M. and Köntges, T. (2016), "Increasing metadata usability for the New Zealand cartoon archive at the alexander Turnbull library", Alexandria: The Journal of National and International Library and Information Issues, Vol. 26 No. 2, pp. 91-106.

Jörgensen, C. (1995), "Image attributes: an investigation”, ProQuest Dissertations Publishing, available at: http://search.proquest.com/docview/304242480/.

Jörgensen, C. (2007), "Image access, the semantic gap, and social tagging as a paradigm shift", in 18th Annual ASIS SIC/CR Classification Research Workshop, available at: doi: 10.7152/acro.v18i1. 12868 (accessed 10 October 2019).

Jörgensen, C., Jaimes, A., Benitez, A. and Chang, S. (2001), "A conceptual framework and empirical research for classifying visual descriptors", Journal of the American Society for Information Science and Technology, Vol. 52 No. 11, pp. 938-947.

Katz, H. (2004), “An historic look at political cartoons”, Nieman Reports, Vol. 58 No. 4, pp. 44-46. 
Kenney, K. (2002), "Building visual communication theory by borrowing from rhetoric", Journal of Visual Literacy, Vol. 22 No. 1, pp. 53-80.

Khan, M.K., Wu, F., Pratt, C.B. and Akhtar, N. (2019), "Satires, narratives and journalistic divides: discourses on free speech in Western and Islamic news media", The Social Science Journal, doi: 10.1016/j.soscij.2019.05.012.

Kline, S. and Hill, M. (2010), "Editorial inkblots: a comparative analysis of presidential election cartoons from 1960, 1980, and 2008”, in Conference Papers - International Communication Association, available at: http://helicon.vuw.ac.nz/login?url=http://search.ebscohost.com/login. aspx? direct $=$ true $\& \mathrm{db}=u f h \& A N=59227597 \&$ site $=$ ehost $-($ accessed 10 October 2019).

Köntges, T. (2016), "Researchers to your driving seats: building a graphical user interface for multilingual topic-modelling in R with shiny", in Digital Humanities 2016: Conference Abstracts, Jagiellonian University \& Pedagogical University, Kraków, pp. 605-607, available at: https://dh2016.adho.org/abstracts/156.

Lægaard, S. (2007), "The cartoon controversy as a case of multicultural recognition", Contemporary Politics, Vol. 13 No. 2, pp. 147-164.

Lægaard, S. (2010), "Normative significance of transnationalism? The case of the Danish cartoons controversy", Ethics and Global Politics, Vol. 3 No. 2, pp. 101-121.

Lakoff, G. and Johnson, M. (1980), The Metaphors We Live by, University of Chicago Press, Chicago, IL.

LaMarre, H.L., Landreville, K.D., Young, D. and Gilkerson, N. (2014), "Humor works in funny ways: examining satirical tone as a Key determinant in political humor message processing", Mass Communication and Society, Vol. 17 No. 3, pp. 400-423.

Lamb, C. (2007), "Drawing power”, Journalism Studies, Vol. 8 No. 5, pp. 715-729.

Lan, C. and Zuo, D. (2016), "Pictorial-verbal metaphors in Chinese editorial cartoons on food safety", Metaphor and the Social World, Vol. 6 No. 1, pp. 20-51.

Landbeck, C. (2002), The Organisation and Categorization of Political Cartoons; an Exploratory Study, Master's thesis, Florida State University, Florida, FL, available at: http://purl.flvc.org/fsu/fd/ FSU_migr_etd-3301 (accessed 10 October 2019).

Landbeck, C. (2008), "Issues in subject analysis and description of political cartoons", in 19th Annual ASIS SIG/CR Classification Research Workshop, doi: 10.7152/acro.v19i1.12854 (accessed 10 October 2019).

Landbeck, C. (2012), “Access to editorial cartoons: the state of the art”, in Pennington, D.R. (Ed.), Indexing and Retrieval of Non-text Information, De Gruyter Mouton, Berlin, pp. 59-79.

Landbeck, C. (2013), The Description and Indexing of Editorial Cartoons: An Exploratory Study, Doctoral dissertation, Florida State University, Florida, FL, available at: http://purl.flvc.org/fsu/ fd/FSU_migr_etd-5469 (accessed 10 October 2019).

Library and Archives Canada (2020), "Political cartoons", available at: http://www.bac-lac.gc.ca/eng/ discover/politics-government/canadian-confederation/Pages/political-cartoons.aspx (accessed 10 October 2019).

Library of Congress (2018), "VRA Core: a data standard for the description of images and works of art and culture", available at: http://www.loc.gov/standards/vracore/ (accessed 10 October 2019).

Library of Congress (2020a), "Encoded archival description", available at: https://www.loc.gov/ead/ (accessed 10 October 2019).

Library of Congress (2020b), “Thesaurus for graphic materials”, available at: http://www.loc.gov/ pictures/collection/tgm/ (accessed 10 October 2019).

Lin, T.Y. and Chiang, W. (2015), "Multimodal fusion in analyzing political cartoons: debates on U.S. Beef imports into taiwan", Metaphor and Symbol, Vol. 30 No. 2, pp. 137-161.

Love, V. (2018). "Ka mua, Ka muri-looking back to look forward", International Association of Sound and Audiovisual Archives (IASA) Journal, Vol. 48, pp. 102-111. 
Mackay, J.B. and Horning, M.A. (2017), "Responding to Charlie Hebdo", Journalism Practice, Vol. 11 No. 9, pp. 1121-1136.

Marín-Arrese, J. (2008), “Cognition and culture in political cartoons”, Intercultural Pragmatics, Vol. 5 No. 1, pp. 1-18.

Mazlack, L.J. and Paz, N.M. (1983), "Resolution of ambiguities in cartoons as an illustration of the role of pragmatics in natural language understanding by computers", Kybernetes, Vol. 12 No. 2, pp. 99-105.

McGurk, C. (2016), "Communicating the value of cartoon art across university classrooms: experiences from the Ohio state university billy Ireland cartoon library and museum", New Review of Academic Librarianship, Vol. 22 Nos. 2-3, pp. 192-202.

Medhurst, M.J. and DeSousa, M.A. (1981), "Political cartoons as rhetorical form: a taxonomy of graphic discourse", Communication Monographs, Vol. 48 No. 3, pp. 197-236.

Mello, W.B. (1998), "Quick communicators: editorial cartoonists in communication overdrive", Annals of the International Communication Association, Vol. 21 No. 1, pp. 379-403.

Mello, W.B. (2007), "Political cartooning in the 21st century: a changing and dynamic future", Critical Studies in Media Communication, Vol. 24 No. 1, pp. 78-80.

Morris, R. (1993), "Visual rhetoric in political cartoons: a structuralist approach", Metaphor and Symbolic Activity, Vol. 8 No. 3, pp. 195-210.

Müller, M.G., Özcan, E. and Seizov, O. (2009), "Dangerous depictions: a visual case study of contemporary cartoon controversies", Popular Communication, Vol. 7 No. 1, pp. 28-39.

Navasky, V.S. (2013), The Art of Controversy: Political Cartoons and Their Enduring Power, Alfred A. Knopf, New York, NY.

Newton, J. (1999), "The centre for the study of cartoons and caricature, University of Kent at Canterbury", Contemporary British History, Vol. 13 No. 4, pp. 170-179.

Oliphant, P. (2004), "Why political cartoons are losing their influence", Nieman Reports, Vol. 58 No. 4, pp. 25-27.

Olson, K.M. and Olson, C.D. (2004), "Beyond strategy: a reader-centered analysis of irony's dual persuasive uses", Quarterly Journal of Speech, Vol. 90 No. 1, pp. 24-52.

Panofsky, E. (1939), Studies in Iconology: Humanistic Themes in the Art of the Renaissance, Oxford University Press, New York, NY.

Panofsky, E. (1955), Meaning in the Visual Arts: Papers in and on Art History, Doubleday, Garden City, New York, NY.

Pedrazzini, A. and Scheuer, N. (2018), "Distinguishing cartoon subgenres based on a multicultural contemporary corpus", European Journal of Humour Research, Vol. 6 No. 1, pp. 100-123.

Rafferty, P. (2011), "Informative tagging of images: the importance of modality in interpretation", Knowledge Organization, Vol. 38 No. 4, pp. 283-298.

Rafferty, P. and Albinfalah, F. (2014), "A tale of two images: the quest to create a story-based image indexing system”, Journal of Documentation, Vol. 70 No. 4, pp. 605-621.

Rafferty, P. and Hidderley, R. (2005), Indexing Multimedia and Creative Works: The Problems of Meaning and Interpretation, Ashgate, Aldershot and Burlington, VT.

Sanadjian, M. (2015), "Icons vs satirical inversions: islamic rule and the 'death of the author' - the murder of the Charlie Hebdo cartoonists in Paris", Social Identities, Vol. 21 No. 3, pp. 294-301.

Schilperoord, J. and Maes, A. (2009), "Visual metaphoric conceptualization in political cartoons", in Forceville, C. and Urios-Aparisi, E., (Eds.) Multimodal Metaphor, Mouton de Gruyter, Berlin, pp. 211-238.

Schnakenberg, U. (2010), "Developing multiperspectivity through cartoon analysis: strategies for analyzing different views of three watersheds in modern German history”, Teaching History, Vol. 139, pp. 32-39. 
Seymour-Ure, C. (2001), "What future for the British political cartoon?”, Journalism Studies, Vol. 2 No. 3, pp. 333-355.

Shatford, S. (1986), "Analyzing the subject of a picture: a theoretical approach”, Cataloging and Classification Quarterly, Vol. 6 No. 3, pp. 39-62.

Shaw, M.J. (2007), "Drawing on the collections", Journalism Studies, Vol. 8 No. 5, pp. 742-754.

Soon, C.Y. (2011), “A cartoonist's resistance”, Inter-Asia Cultural Studies, Vol. 12 No. 3, pp. 420-429.

Sorrm, E. and Steen, G. (2013), "Processing visual metaphor", Metaphor and the Social World, Vol. 3 No. 1, pp. 1-34.

Stvilia, B., Jörgensen, C. and Wu, S. (2012), "Establishing the value of socially-created metadata to image indexing", Library and Information Science Research, Vol. 34 No. 2, pp. 99-109.

The Washington Post (2019), "GB Trudeau's Doonesbury" available at: http://doonesbury. washingtonpost.com/ (accessed 10 October 2019).

Ulubeyli, S., Arslan, V. and Kivrak, S. (2015), "A semiotic analysis of cartoons about occupational health and safety issues in the construction workplace", Construction Management and Economics, Vol. 33 Nos. 5-6, pp. 467-483.

Veninga, J.E. (2016), "Echoes of the Danish cartoon crisis 10 Years later: identity, injury and intelligibility from copenhagen to Paris and Texas", Islam and Christian-Muslim Relations, Vol. 27 No. 1, pp. 25-34.

Winget, M. (2009), "Describing art: an alternative approach to subject access and interpretation", Journal of Documentation, Vol. 65 No. 6, pp. 958-976.

Wu, Y. (2013), "Indexing historical, political cartoons for retrieval”, Knowledge Organisation, Vol. 40 No. 5, pp. 283-294.

Yllmaz, F. (2011), "The politics of the Danish cartoon affair: hegemonic intervention by the extreme right", Communication Studies, Vol. 62 No. 1, pp. 5-22.

Zavalina, O.L., Palmer, C.L., Jackson, A.S. and Han, M. (2009), "Evaluating descriptive richness in collection-level metadata", Journal of Library Metadata, Vol. 8 No. 4, pp. 263-292.

Zhang, J., Ribbens, K. and Zeeman, R. (2013), "The digital archiving of historical political cartoons: an introduction", in Presented at the 13th Dutch-Belgian Workshop on Information Retrieval, available at: https://www.researchgate.net/publication/290040732/download (accessed 10 October 2019).

Zhou, W., Li, H. and Tian, Q. (2017), Recent advance in content-based image retrieval: a literature survey, available at: https://arxiv.org/pdf/1706.06064.pdf (accessed 10 October 2019).

\section{Further reading}

China Daily (2019), "Cartoons - China daily", available at: http://www.chinadaily.com.cn/opinion/ cartoon/index.html (accessed 10 October 2019).

Hutchins, W.J. (1978), “The concept of 'aboutness' in subject indexing”, ASLIB Proceedings, Vol. 30 No. 5, pp. 172-181.

\section{Corresponding author}

Chern Li Liew can be contacted at: ChernLi.Liew@vuw.ac.nz

For instructions on how to order reprints of this article, please visit our website:

www.emeraldgrouppublishing.com/licensing/reprints.htm

Or contact us for further details: permissions@emeraldinsight.com 